\title{
ATRATORES SISTÊMICOS E A DIFERENCIAÇÃO INTERNA DO DIREITO NA GESTÃO JURÍDICA DO RISCO BIOTECNOLÓGICO
}

\section{SYSTEMIC ATTRACTORS AND THE INTERNAL DIFFERENTIATION OF LAW IN BIOTECHNOLOGICAL RISK LEGAL}

MANAGEMENTALTA TEXTO

\section{PAULO ROBERTO RAMOS ALVES}

Doutor em Direito pela Universidade do Vale do Rio dos Sinos (UNISINOS); Estágio Pós-Doutoral pela Universidade de Passo Fundo (UPF); Professor na Universidade de Passo Fundo (UPF) e na Universidade do Oeste de Santa Catarina (UNOESC); Advogado; pauloalvess@yahoo.com.br

\section{RESUMO}

Objetivo: O presente artigo tem como objetivo a análise do desenvolvimento interno de um subsistema comunicativo no interior do Direito. Para tanto, parte-se do reconhecimento da problemática do risco biotecnológico como vetor de condução à formação de uma racionalidade parcial interna, suficientemente complexa para alcançar a possibilidade de gestão jurídica do risco biotecnológico.

Metodologia: Trata-se de um estudo amparado na metodologia de observação sistêmica, e em pesquisas bibliográficas.

Resultados: A visualização do risco biotecnológico como atrator evolutivo condicionante/condicionado não soluciona a problemática da contingência da distinção geneticamente-aplicável/geneticamente-inaplicável; mas, ao contrário, afirma a possibilidade de que, diante da não solução do problema, existem caminhos passíveis de construção pelo Direito. O risco biotecnológico, quando percebido mediante a distinção Direito/não-Direito, pode ser observado na forma de um atrator juridicamente condicionante, constrangendo o sistema à evolução a partir de situações que não mantém qualquer relação teleológica ou determinística, mas sim com a deriva estrutural presente na história da autopoiese sistêmica. 
Contribuições: Ao assumir-se a possibilidade de evolução do sistema jurídico, o estudo dá como contribuição a informação de que o risco biotecnológico passa a influenciar nas possíveis trajetórias adotadas pelo sistema, não a condicionando no sentido lato da expressão, mas possibilitando ao sistema utilizar o risco biotecnológico como norteador de suas operações internas (atrator juridicamente condicionante), bem como de sua capacidade de produzir ressonâncias direcionadas em outros sistemas sociais (atrator juridicamente condicionado).

PALAVRAS-CHAVE: Evolução; diferenciação; indeterminação; risco biotecnológico.

\section{ABSTRACT}

Objective: To analyze the internal development of a communicative subsystem within the Law. Therefore, it is started by recognizing the problem of biotechnological risk as a driver for the formation of a partial internal rationality, which is complex enough to achieve the possibility of legal management of biotechnological risk.

Methodology: This is a study based on the methodology of systemic observation and bibliographic research.

Results: The visualization of biotechnological risk as a conditioning/ conditioned evolutionary attractor does not solve the issue of the contingency of geneticallyapplicable/genetically-inapplicable distinction; but, on the contrary, it affirms the possibility that, given the non-solution of the issue, there are paths that can be built by Law. Biotechnological risk, when perceived through the Legal/non-Legal distinction, can be observed in the form of a legally conditioning attractor, constraining the system to evolution from situations that have no teleological or deterministic relationship, but rather with structural drift present in the history of systemic autopoiesis.

Contributions: By assuming the possibility of evolution of the legal system, the study contributes to the information that the biotechnological risk starts to influence the possible trajectories adopted by the system, not conditioning it in the broad sense of the expression, but enabling the system to use biotechnological risk as a guide to its internal operations (legally conditioning attractor), as well as its ability to produce targeted resonances in other social systems (legally conditioned attractor).

KEYWORDS: Evolution; differentiation; indeterminacy; biotechnological risk. 


\section{INTRODUÇÃO}

Evolução, diferenciação, indeterminação. Tais elementos emergem diafanamente quando se observa a sociedade desde uma perspectiva autopoiética. Sendo a evolução observada como um processo que se relaciona intrinsecamente com a habilidade da sociedade em resolver problemas por ela própria criados, é razoável que o risco seja percebido como um elemento de evidente importância naqueles processos de diferenciação funcional que caracterizam a evolução social.

Claro está que o Direito não é um sistema que opera de forma determinística. O enfretamento do Direito sob sua consideração como sistema autopoiético exclui qualquer possibilidade de que este opere sob a chancela de premissas deterministas ou teleológicas. A sociedade e seus subsistemas parciais operam sob uma constante produção de complexidade que, sob a ótica de outros observadores, afirma-se como complexidade desordenada, encontrando alguma lógica a partir da atribuição do sentido binário que tão somente o observador é capaz de realizar.

O presente texto, amparado na metodologia de observação sistêmica, tem por escopo a análise do desenvolvimento interno de um subsistema comunicativo no interior do Direito. Para tanto, parte-se do reconhecimento da problemática do risco biotecnológico como vetor de condução à formação de uma racionalidade parcial interna suficientemente complexa para alcançar a possibilidade de gestão jurídica do risco biotecnológico.

\section{BIOTECNOLOGIA E DIFERENCIAÇÃO: OBSERVAÇÕES PRELIMINARES SOBRE A EVOLUÇÃO DO DIREITO}

Toda e qualquer alteração nas estruturas sociais depende de um lento e gradativo movimento da sociedade. Mesmo as rupturas revolucionárias mais abruptas verificadas na história ${ }^{1}$ não se mostraram capazes de transformar a realidade da noite

${ }^{1}$ Cite-se como exemplos a Revolução Francesa de 1789 e a Revolução Russa de 1917. 
para o dia, tornando-se forçoso o reconhecimento quanto à impossibilidade de alteração social a partir de um único centro gravitacional (LUHMANN, 1993, p.217218). A evolução social, portanto, relaciona-se intrinsecamente com a continuidade de um movimento comunicativo que é, em última análise, condição de existência dessa mesma sociedade.

Ao se falar de evolução, três perspectivas devem estar muito bem delimitadas no debate, quais sejam, a teoria da evolução de Darwin, a autopoiese biológica de Maturana e Varela, por fim, as perspectivas sistêmico-autopoiéticas da sociologia de Luhmann e da sociologia jurídica de Teubner. Essas três noções - a última como formação evolutiva/diferenciada das anteriores, a qual de fato traz a possibilidade de uma adequada análise do problema ora perseguido - representam fortes rupturas com suas respectivas tradições científicas precedentes, fornecendo um conjunto teórico bastante robusto para se analisar a possibilidade de processos de diferenciação jurídica como aquisições evolutivas.

Baseado nos conceitos de seleção natural e evolução, Darwin sustentou, na segunda metade do século XIX, a existência de um conjunto de processos e operações que permitiam um constante movimento (natural) direcionado a assegurar aquelas condições estruturais que viabilizassem a sobrevivência do mais apto. Para tanto, Darwin reconheceu que a evolução das espécies dependia de um conjunto de operações de variação, acumulação e efetivação que, após constituído, tendia a voltar a apresentar novas variações que, caso favoráveis, seriam preservadas. Tais variações, por sua vez, serão submetidas a novas variações, continuamente. ${ }^{2}$

A dinâmica da evolução darwiniana pressupunha que "a seleç̧ão natural só age se tal for vantajoso para cada indivíduo" (DARWIN, 2008, p.88), colocando em evidência a noção segundo a qual a evolução afirma-se sob uma perspectiva de constante adaptação dos organismos vivos ao seu meio circundante. Em Darwin, a adaptação é elemento central. A vida é uma constante batalha por adaptação, sendo

\footnotetext{
2 DARWIN, 2009, p. 88: "Pode dizer-se, metaforicamente, que a selecção natural: trabalha sem parar, todas as horas de todos os dias da semana, por todo o mundo, analisando as variações mais ligeiras; rejeita as que são nocivas, conserva e acumula todas as que são benéficas; trabalha em silêncio, imperceptivelmente, a qualquer hora e em qualquer lugar, sempre que uma oportunidade se apresenta, para melhorar cada ser vivo na relação com as suas condições de vida, orgânicas e inorgânicas".
} 
a sobrevivência dos seres vivos uma questão de maior ou menor adaptação ao seu meio ambiente. Sob tal noção, aquelas espécies melhor adaptadas sobrevivem enquanto as menos adaptadas tenderão a perecer.

O elemento chave da seleção natural, portanto, é a capacidade dos seres vivos em se submeterem a um contínuo acúmulo de experiências que, em determinado momento, de acordo com as exigências ambientais, permitirá que sua estrutura biológica utilize esse conjunto como condição de variação. Na perspectiva darwiniana a evolução relaciona-se com a capacidade dos seres vivos em constantemente buscarem a adaptação ao seu meio circundante, sendo sintetizada na máxima da sobrevivência do mais apto.

Essa construção foi assimilada sociologicamente especialmente pelo pensamento sociobiológico ${ }^{3}$, mostrando-se extremamente inadequada à explicação das complexas relações sociais contemporâneas. Ao analisar socialmente a construção de Darwin, o aspecto linear e progressista da evolução assumida pela sociobiologia conduziria a irresistíveis questionamentos: poderia a gestão do risco biotecnológico encontrar um ponto de estabilização desde tal ótica? Ou, com base na sobrevivência do mais apto haveria alguma possibilidade social de controle de tal risco? A tentativa de responder tais perguntas desde a perspectiva da seleção natural darwiniana seria por demais ingênua e limitada, o que redundaria em, no mínimo, dois problemas básicos que se manifestariam desde duas perspectivas teóricometodológicas diversas: primeiro, se considerada desde a observação da sociologia tradicional ${ }^{4}$, na desconsideração para com 0 indivíduo; segundo, se considerada desde a ótica sistêmico-autopoiética, no problema da desdiferenciação (NAFARRATE, 2012. p. 58).

\footnotetext{
${ }^{3}$ Anote-se, sobretudo, a construção progressita de Herbert Spencer, a qual Luhmann ironiza definindoa como descuidada, conforme é possível observar em LUHMANN, 2007, p. 333, nota 18. Sobre o pensamento progressista de Spencer vide SPENCER, 1939. p. 12-15.

${ }^{4}$ Por sociologia tradicional anote-se, no contexto trabalhado, a perspectiva do indivíduo como membro da sociedade. Tal pensamento teve, em Parsons, talvez seu último representante significativo. Ainda que amparado em um conceito sistêmico funcional-estruturalista, Parsons não prescinde da presença do homem no que entende por sociedade, como o faz posteriormente Luhmann. Vide PARSONS, 1974. p. 18.
} 
A teoria da seleção natural darwiniana não se mostra compatível com a noção de autopoiese por uma razão evidente: ao se afirmar o sucesso do mais apto, necessariamente está-se realizando uma distinção, o que importa na exclusão do menos apto. Os problemas que essa noção apresenta podem ser visualizados exemplificativamente a partir da comparação entre o anacronismo entre os sistemas do Direito e da Economia. Se o aforismo darwiniano da sobrevivência do mais apto for levado as suas últimas consequências no campo social, forçosamente ter-se-ia que reconhecer que o Direito - então menos apto - sucumbiria aos desígnios do sistema econômico, perdendo sua autonomia. Via de consequência, as possíveis construções jurídicas produzidas a partir da consideração do risco biotecnológico far-se-iam possíveis tão somente a partir de um cálculo monetário quanto a possibilidade da gestão jurídica de risco, o que naturalmente não pode ser aceito desde a ótica do sistema do Direito.

Muito embora a ótica darwiniana se mostre insuficiente para se analisar a evolução da sociedade, foi essa perspectiva que, ainda na biologia, conduziu à teorização que culminou no conceito de autopoiese. Foi o questionamento quanto aos processos biológicos que caracterizam os seres vivos que levou Maturana e Varela a discordar que a evolução ocorresse com base na seleção natural ${ }^{5}$, passando a observar a evolução como elemento baseado na deriva natural dos seres vivos. Essa perspectiva desloca a seleção natural posta por Darwin do nível de condição evolutiva para o de consequência da evolução ${ }^{6}$, fazendo emergir o revolucionário conceito de

\footnotetext{
${ }^{5}$ ROMESÍN; VARELA, 2001, p. 127: "Como muitas das descrições sobre a evolução biológica que herdamos dos textos escolares, essa também é inadequada [...]. $\mathrm{Na}$ melhor das hipóteses, o observador pode introduzir um padrão de comparação ou referência, que the permita fazer comparações e falar da eficácia na realização de uma função. [...] As comparações sobre eficácia pertencem ao domínio de descrições feitas pelo observador, e não têm relação direta com o que acontece com as histórias individuais de conservação da adaptação. Para resumir: não há sobrevivência do mais apto, o que há é sobrevivência do apto. Trata-se de condições necessárias, que podem ser satisfeitas de muitas maneiras, e não de otimização de critérios alheios à própria sobrevivência";

${ }^{6}$ ROMESÍN; MPODOZIS, 1992, p. 41: "la estabilidad histórica de los seres vivos es dinámica en tanto fenómeno sistémico, y que el cambio en la deriva del vivir surge de un proceso conservador. [...] Sin duda la conservación genética es parte de la conservación de los fenotipos ontogénicos y modos de vida, pero en tanto no los determina, está abierta a un cambio que no vemos porque no lo esperamos. Los seres vivos se realizan el fenotipo, y es precisamente el ocultamiento de la variabilidad genética que esto implica lo que ha permitido que ocurra la evolución como proceso de deriva filogénica natural. La epigénesis es un fenómeno sistémico, y es precisamente eso lo que ha resultado en la diversificación
} 
autopoiese como elemento explicativo das complexas relações integrativas que caracterizam os sistemas biológicos.

Se a seleção natural darwiniana conduz ao problema da desdiferenciação entre sistema e ambiente - posto que parte do pressuposto de que o ambiente imporá ao sistema alterações que lhe garantirá a sobrevivência ou lhe fará perecer - o conceito de autopoiese permite que se observe os sistemas vivos como intrinsecamente adaptados, reconhecendo-se que " [...] o que há é apenas a conservação da adaptação e da autopoiese, num processo em que o organismo e ambiente permanecem num contínuo acoplamento estrutural" (ROMESÍN; VARELA, 2001, p.130). Quando observam a autopoiese como invariante (ROMESÍN; VARELA, 2001, p.131), Maturana e Varela anotam que a evolução condiciona-se àqueles processos internamente construídos que asseguram a uma espécie sua continuidade. É a invariabilidade da autopoiese enquanto fenômeno constitutivo dos sistemas vivos que permite a contínua reconstrução e permanente adaptação à ambiência sistêmica. Autopoiese pressupõe a adaptação. Se um ser vivo não é adaptado, ele perecerá, não sendo razoável, desde tal perspectiva, falar-se em melhor ou pior adaptação como queria Darwin.

Todas as operações tendentes a conservar a autopoiese dos sistemas biológicos serão elementos internamente construídos pelos seres vivos, de modo que o próprio processo cognitivo se torna algo que apenas é possível desde o ponto de observação do sistema que observa. Dito de outro modo, a conservação da autopoiese depende de que haja uma contínua observação do meio circundante, a qual apenas existe sob a forma de uma construção própria de um observador. $O$ ambiente não colabora ou prejudica o sistema com o fornecimento direto de informações, mas fornece elementos que serão percebidos e assimilados biologicamente de acordo com aquelas condições e limites que o próprio sistema neste caso, um ser vivo qualquer - internamente possibilitará.

É tal condição biológica que assegura os passos seguintes da evolução, pois no momento em que é reconhecida a incapacidade de contato entre sistema e

de los seres vivos como sistemas que existen sólo bajo las condiciones en que conservan organización y adaptación. La selección natural es un resultado, no un mecanismo generativo". 
ambiente, bem como da consequente impossibilidade de que o meio externo oriente ou defina os critérios operativos do sistema, esse passa a ser constrangido a uma contínua produção daqueles elementos que, em última análise, serão reempregados em novos processos tendentes a assegurar sua preservação. Tudo isso leva ao irrecorrível reconhecimento, por Maturana e Varela, da evolução como deriva natural, isto é, na visão de que "todo o sistema autopoiético é uma unidade de múltiplas interdependências" (ROMESÍN; VARELA, 2001, p.131) onde o estado atual do sistema depende de variáveis possíveis que, a todo o momento, sofrem alterações, condicionando os estados posteriores do sistema à sua permanente relação com o meio externo.

Para além do darwinismo social, onde pretensamente a aptidão à melhor adaptação poderia sugerir a continuidade de grupos sociais ${ }^{7}$, a perspectiva autopoiética foi incorporada à moldura sociológica por Luhmann que, inspirado na dialética hegeliana ${ }^{8}$, identificou a sociedade como 0 conjunto de todas as comunicações possíveis em contraste àquilo que não é comunicação, inclusive realocando o indivíduo como integrante no entorno da sociedade, dela não fazendo parte. ${ }^{9} \mathrm{O}$ corte epistemológico realizado por Luhmann permitiu que a dualidade hegeliana fosse somada à perspectiva autopoiética biologicamente originária, fazendo emergir um radical conceito de sociedade e, consequentemente, uma forma inédita de se observar seus processos evolutivos.

Se a evolução é possível, é de ser afirmado que "un sistema sólo es capaz de evolución, y lo será siempre, cuando determinados problemas internos se agravan hasta tal punto que ya sólo pueden resolverse con ayuda de modificaciones

\footnotetext{
7 Poder-se-ia pensar, a tal respeito, o predomínio dos interesses de maiorias em detrimento das aspirações de minorias, por exemplo, étnicas, culturais, econômicas, entre outras. Quando aplicada socialmente, a teoria da seleção natural inegavelmente redunda em problemas dessa ordem, impondo àqueles considerados menos aptos condições sociais de exclusão.

${ }^{8}$ Hegel observa o desenvolvimento sob o argumento de que "o aperfeiçoamento é na verdade algo quase tão indeterminado com o é a mutabilidade em geral; ele não tem meta, objetivo ou um padrão de mudança. $O$ melhor, o mais aperfeiçoado a que se pressupõe chegar é algo inteiramente indeterminado". (HEGEL, 2001. p. 105-106).

${ }^{9}$ Tal aspecto é central na obra de Luhmann, onde se verifica uma nítida separação entre os domínios biológicos, psíquicos e sociais, percebendo-se o indivíduo como uma construção apenas possível a partir de acoplamentos entre essas três esferas existenciais e, logo, não havendo uma determinação vertical entre sociedade e indivíduo. (LUHMANN, 1997. p. 118-119 e 127).
} 
estructurales" (LUHMANN, 1991, p.27). A tal afirmação, Luhmann acrescenta uma importante observação quando sublinha que o agravamento de problemas internos não significa que os problemas sistêmicos produzam por si próprios suas soluções ou que, ainda, apontem para eventual teleologia no âmbito das operações sistêmicas. Antes, a determinação dos problemas diante do reconhecimento da insuficiência estrutural sistêmica é o que permite a busca por soluções que apenas serão possíveis a partir de novas percepções internamente construídas.

A perspectiva luhmanniana, portanto, rompe com a máxima darwiniana da sobrevivência do mais apto. Alicerçado na autopoiese de Maturana e Varela, Luhmann parte do pressuposto de que a sobrevivência não depende de uma melhor aptidão à adaptação mas, sim, à própria capacidade de adaptação enquanto requisito para a autopoiese. Um sistema é adaptado ou não é. Ainda que frágil - sob outros pontos de observação - um sistema autopoiético sempre será adaptado ao seu meio circundante, não sendo possível defender uma busca por adaptação (LUHMANN, 1991, p.25). Necessariamente o sistema produzirá continuamente aqueles elementos que asseguram a continuidade dessa adaptação.

A impossibilidade de uma melhor ou pior adaptação do sistema ao seu meio circundante passa a ser o marco central de uma teoria que tenha pretensão de explicar a sociedade desde a perspectiva de sua evolução. A sociedade, portanto, não encontra como condição de sua continuidade - e evolução - a melhor adaptação ao seu meio. Quando se observa o sistema social na forma da unidade da diferença entre comunicação e não-comunicação, como consequência lógica o problema da melhor ou pior adaptação é transposto para o problema da continuidade de suas operações autopoiéticas ou, em outras palavras, para a capacidade do sistema em permanentemente reproduzir seus elementos constitutivos ante os influxos originados em seu entorno.

Dito de forma mais direta, se a sociedade existe na forma de um sistema autopoiético comunicativamente omniabarcador, é razoável reconhecer que essa mesma sociedade é também adaptada ao seu meio. A partir de tal constatação, a discussão que emerge refere-se à continuidade das operações sociais. Ao ser comunicativamente produzido, o sistema social reclama uma constante produção de 
comunicações como condição para a continuidade de sua autopoiese. ${ }^{10} \mathrm{~A}$ sociedade reclama a produção de sempre renovadas comunicações - o que se dá mediante a produção de diferença -, cujos critérios para sua identificação repousam sob a ótica constituída com base na atribuição de sentido ${ }^{11}$ que os sistemas funcionais parciais apresentam.

Nessa ótica, evolução importa na capacidade de conservação/reprodução do sistema a partir de uma multiplicação daqueles pressupostos sob os quais torna-se possível o desenvolvimento de determinada ordem sistêmica (LUHMANN, 2007, p.328). Um sistema autopoiético - e, por isso, necessariamente adaptado - conduz a uma contínua produção de complexidade como requisito para suas operações posteriores. A historicidade sistêmica mostra-se como elemento intrinsecamente relacionado à sua capacidade evolutiva. Quanto mais complexo um sistema for, maior será sua capacidade de reação diante de influxos externamente produzidos. Essa afirmação terá consequências drásticas para a internalização do risco biotecnológico e a formação de uma esfera comunicativa diferenciada no Direito, conforme será adiante observado.

Quando a análise do risco biotecnológico é realizada sob as lentes sistêmicas, inegavelmente pode-se perceber que sua gestão é um processo que depende de elementos evolutivos do sistema. Sendo a evolução da sociedade pressuposta como condição à gestão de risco, uma constatação óbvia se mostra necessária: a possível gestão jurídica do risco - construído a partir da reiteração da comunicação identificada semiautonomamente sob a forma geneticamente-aplicável/geneticamente-inaplicável

10 Depreende-se daí que é a intrínseca capacidade de produzir comunicações que assegura à sociedade sua continuidade. Mesmo a não-comunicação apenas pode ser observada e descrita pela sociedade sob a forma comunicativa. É a aptidão em atravessar a diferença comunicação/nãocomunicação, inclusive tematizando comunicativamente aquilo que não é comunicação que permite que a sociedade seja observada como um sistema autopoiético e, por isso, capaz de evoluir de acordo com seus pressupostos operativos. Sendo vista como comunicação, a própria noção de estabilidade é frontalmente fragilizada diante dessa perspectiva. A estabilização da sociedade apenas é possível na ótica de um observador, não sendo razoável pensar em condensar a estabilidade ao nível estrutural da sociedade. Estruturar a estabilidade equivaleria condenar o sistema à perda de sua capacidade autopoiética, pois, se as estruturas são possíveis unicamente a partir da delimitação de um âmbito de possibilidades (complexidade), apenas a sua referência a operações é o que expõe a sociedade à evolução. (LUHMANN, 2007, p. 339).

${ }^{11}$ LUHMANN, 1998, p. 87: "El sentido la forma general de la disposición autorreferencial hacia la complejidad que no puede ser caracterizada por contenidos determinados (con exclusión de otros)". 
- tão somente é possível com referência a processos de diferenciação que ocorrem na sociedade e, na presente situação, no Direito, impondo a lógica evolutiva igualmente ao campo jurídico.

Teubner bem observou o Direito quando partiu do pressuposto de que seus processos evolutivos não se dão de forma teleológica, orientando-se finalisticamente, mas sim teleonomicamente, no qual se constrói a realidade a partir da continuidade das operações sistêmicas possíveis em determinado momento, isto é, a partir da combinação de certos programas bem sucedidos, da eliminação de outros que tenham se mostrado falhos, na recombinação de programas onde a manutenção inalterada não se mostre possível, etc. ${ }^{12}$ Nessa perspectiva, o conceito de evolução não importa em melhoria ou progresso. A evolução passa a se relacionar com os processos de diferenciação por meio dos quais o sistema adapta-se à realidade do momento, tornando-se capaz de produzir respostas de acordo com a binariedade específica que o caracteriza. ${ }^{13}$

Também distante de noções evolutivas condicionadas a melhorias ou progresso, Teubner elenca três elementos centrais de uma teoria da sociedade com vistas a uma observação teórica dos processos de evolução jurídica, identificando-os pela possibilidade de interação entre variação, seleção e retenção, pela combinação entre desenvolvimento ontogenético e filogenético e pela co-evolução entre Direito, Sociedade e outros sistemas parciais (TEUBNER, 1989, p.104).

O primeiro elemento - variação, seleção e retenção - refere-se à constante interação jurídica a partir da diferença endógeno/exógeno. O Direito é construído

\footnotetext{
12 TEUBNER, Gunther. O direito como sistema autopoiético. Lisboa: Fundação Calouste Gulbenkian, 1989. p. 98: "a evolução não é teológica (orientada finalisticamente) mas meramente 'teleonómica', sendo construída na continuidade do sistema existente de acordo com particulares regras ou leis, recombinando programas bem sucedidos e eliminando outros falhados. Embora esse desenvolvimento seja irreversível, ele não é garante da condução do sistema a um estado 'melhor' ou 'pior' que o seu predecessor, assim como não assegura maios viabilidade ou segurança, mais 'sorte' ou 'consciência'". ${ }_{13}$ Todo o movimento da sociedade, por sua vez, evolui mediante o estabelecimento de um sentido particular para as comunicações. A recursividade de determinadas comunicações, como a jurídica, econômica, religiosa ou política, promove, via de consequência, a evolução sistêmica por meio de processos de diferenciação funcional. A evolução social relaciona-se com a especificação de funções particulares por determinados sistemas. Vide LUHMANN, 2007, p. 393.
} 
internamente e apenas direito produz direito ${ }^{14}$. Essa perspectiva conduz à necessária compreensão de que a estrutura jurídica (normas, processos, dogmática) produz uma realidade própria, interna ao sistema do Direito. A endogenia jurídica, na ótica de Teubner, é influenciada por fatores exógenos (sociais), havendo uma constante troca entre Direito e Sociedade. Os fatores endógenos e exógenos do Direito funcionam mediante sucessivas operações de variação, seleção e retenção, garantindo à estrutura normativa (leis) a função de variação, à estrutura procedimental (processos) a função de seleção e à estrutura dogmática a função de retenção (TEUBNER, 1989, p.104 e 110). Essa mesma perspectiva é encontrada em Luhmann quando demonstra que a evolução do Direito opera de modo circular diante dos influxos do entorno. Aqui, a evolução se dá quando o sistema responde às perturbações com variação interna, seleciona operações relevantes e estabiliza a comunicação, tornando a impulsionar outras inovações, circularmente (LUHMANN, 2005, p.339):

A endogenia jurídica pressupõe o equilíbrio de um constante paradoxo sistêmico definido pela abertura do Direito por meio de seu fechamento. A afirmação de Teubner sobre a produção do Direito pelo Direito não pressupõe o retorno às raízes positivistas oitocentistas, mas torna claro que o Direito é (auto)determinado por sua própria recursividade e, consequentemente, pela possibilidade de assimilação dessa complexidade pelas estruturas internas do sistema jurídico que, mediante seu código, as processará, permitindo a evolução do Direito e da Sociedade.

Ao condicionar a evolução do Direito a operações de variação, seleção e retenção, Teubner igualmente passa a reconhecer o desenvolvimento ontogenético e filogenético como um segundo elemento nos processos evolutivos. Tal elemento permite se observar que "[...] a combinação do desenvolvimento ontogenético e filogenético no Direito, ou seja, a interrelação entre processo jurídico e cultura jurídica, deve ser vista como uma interacção entre dois ciclos comunicativos" (TEUBNER,

\footnotetext{
${ }^{14}$ LUHMANN, El derecho de la sociedad, 2005, p. 106: "En ello la producción de estructuras es un asunto circular ya que las operaciones para poder referirse recursivamente a otras operaciones necesitan construir estructuras. No sólo la producción de operaciones mediante operaciones, sino también, y sobre todo, la condensación y la confirmación de estructuras mediante operaciones que se orientan a tales estructuras, es la realización de la autopoiesis. Bajo este punto de vista nosotros veremos al sistema de derecho con un sistema que se determina a sí mismo."
} 
1989, p.122), fazendo com que o Direito - por meio da centralidade dos tribunais (LUHMANN, 1990, p.160-163) - produza decisões baseadas em decisões anteriormente tomadas e que se afirmarão, de igual maneira, como ponto de partida para outras decisões, possibilitando o desenvolvimento autorreferencial do sistema jurídico.

Se, por um lado, o Direito combina processos interativos entre filogênese e ontogênese no sentido de que tais relações possibilitam complexas interações comunicativas intrajurídicas, viabilizando trocas entre processo e cultura jurídica, bem como se, por outro lado, o Direito harmoniza operações internas de variação, seleção e retenção, um terceiro elemento pode ser visto a partir dessas interações: a inegável co-evolução entre Direito e Sociedade. Esse terceiro elemento informa que, no cenário moldado a partir do reconhecimento de processos co-evolutivos, "[...] a selecção das mudanças e inovações no direito não é apenas imputável à autopoiesis do próprio sistema jurídico, mas também [...] à autopoieisis doutros subsistemas sociais e da própria sociedade" (TEUBNER, 1989, p.123) enquanto sistema comunicativo omniabarcador.

A perspectiva luhmanniana na qual a teoria dos sistemas "descreve as relações sob o ponto de vista da diferença entre o sistema e o ambiente" (LUHMANN, 1990), bem como seu reaproveitamento e inovação sob o prisma do sistema jurídico, por Teubner, quanto à existência de processos co-evolutivos entre Direito e Sociedade, conduz a algumas constatações necessárias:

1) O Direito individualiza-se com base em um código, definido por Luhmann como a unidade da diferença entre direito e não-direito (LUHMANN, 2005, p.228-229) Essa diferença fundamental é o que permitirá que o direito produza sua realidade autônoma e autorreferencial, bem como construa sua realidade sem qualquer determinação exterior.

2) A circularidade das operações jurídicas aponta para formas evolutivas alcançadas a partir de determinados processos de seleção, variação e retenção que apenas podem ser realizados juridicamente, ou seja, são as estruturas jurídicas manifestas pela legislação, dogmática e sua discussão pela via processual que conduzem à uma contínua produção de comunicações jurídicas que servirão de base 
para novas comunicações jurídicas, alterando-se o Direito com base nessa constante circularidade.

3) A interrelação entre filogênese e ontogênese é reconstruída comunicativamente sob a perspectiva de constantes interações entre processos jurídicos determinados e o sistema do Direito como um todo, viabilizando que a aprendizagem jurídica dependa, por um lado, de uma constante produção de diferença pela via processual (ontogênese) e, por outro, a assimilação em nível sistêmico por meio da elevação de uma aquisição processual ao patamar de estrutura jurídica (filogêse).

4) Tal movimento autopoiético depende de uma co-existência entre Direito e Sociedade. Em outras palavras, muito embora autônomo, o Direito apenas existe na Sociedade, logo, suas operações resultam de perturbações emanadas de outras esferas comunicativas, assim como o resultado de suas operações produzirá novas perturbações que deverão ser assimiladas sob o ponto de observação próprio de outros sistemas funcionais. A evolução do Direito na sociedade funcionalmente diferenciada torna-se intrinsecamente dependente de igual evolução em outros campos sociais, falando-se, portanto, em processos co-evolutivos entre Direito e sociedade.

Diante de tais considerações é possível questionar, com Luhmann, se no interior de um sistema autopoiético (Direito) que se desenvolve no âmbito interno de outro sistema autopoiético (sociedade) é possível a emergência de níveis recursivos de comunicações jurídicas que permitam seu enclausuramento autorreferencial e, com isso, fomentem processos de diferenciação no interior de um sistema já funcionalmente diferenciado. Em outras palavras, questiona-se "si en sentido estricto dentro de los sistemas autopoiéticos pude haber subsistemas autopoiéticos" (LUHMANN, 2005, p.304) como resultado e, paradoxalmente, como condição de processos evolutivos.

A essas constatações, e a partir delas, poder-se-ia acrescentar algumas observações atinentes ao próprio risco biotecnológico no âmbito do Direito, notadamente o fato de que aquele torna-se tema comunicativo no interior do sistema jurídico, identificando-se mediante a forma direito/não-direito a partir da produção de 
decisões desde o centro do sistema, bem como pela produção legislativa periférica com referência ao tema (LUHMANN, 1990, p.160-163). Por outro lado, a realidade e historicidade do sistema, já transformadas pela assimilação de tal comunicação mantêm-se em movimento, tendo no risco das biotécnicas um elemento que contribui para a circularidade das operações jurídicas.

No tocante aos aspectos filogênicos e ontogênicos do sistema, pode-se notar que o risco biotecnológico, quando tematizado processualmente, induz o sistema a assimilá-lo sob a forma de comunicação jurídica. Dito de outro modo, enquanto comunicação assimilada pela via processual ${ }^{15}$, o risco biotecnológico passa a se relacionar, em um primeiro momento, com a capacidade de percepção jurídica quanto à necessidade de seu enfrentamento, possibilitando, em um segundo momento, sua cristalização temporal sob a forma de estrutura sistêmica, o que se traduz pela formação de expectativas normativas (LUHMANN, 1983, p.109), como pode ser observado no próprio desenvolvimento da Lei 11.105/2005.

Ora, se a evolução do Direito depende também de critérios racionalmente construídos desde outros pontos de observação, é razoável afirmar que uma possível gestão do risco biotecnológico - inclusive por ser um problema originado além das fronteiras jurídicas - passa pela possiblidade de que a realidade construída pelo sistema do Direito observe juridicamente outras realidades sociais. Em síntese, a evolução do sistema jurídico depende da igual evolução de outros subsistemas sociais e de constantes trocas comunicativas entre si.

Enquanto a autonomia do Direito é uma realidade perseguida desde as primeiras bandeiras que anunciavam o constitucionalismo ${ }^{16}$, essa mesma autonomia, se isoladamente considerada, redunda no risco do fechamento e, via de consequência, no problema do enclausuramento sistêmico para com a sociedade.

\footnotetext{
15 Paradigmático no Brasil é o caso envolvendo a soja geneticamente modificada roundup ready, produzida pela empresa norte-americana Monsanto.

${ }^{16}$ Refira-se nesse aspecto a formação inicial do constitucionalismo como vinculado à autonomização do Direito face à Política. A tal respeito, quando analisa a noção de Constituição sob a forma de uma aquisição evolutiva da sociedade, Luhmann salienta que "o conceito de Constituição, contrariamente ao que parece à primeira vista, é uma reação à diferenciação entre Direito e Política, ou dito com uma ênfase ainda maior, à total separação de ambos os sistemas de funções e à consequente necessidade de uma religação entre eles". (LUHMANN, 1996, p. 4)
} 
Logo, se "o sistema fechado não é possível" e "o sistema aberto é inútil", como quer Rocha (2005, p.38), importando por um lado, no solipsismo cognitivo sistêmico e, por outro, na desdiferenciação em relação ao seu entorno, a continuidade das operações autopoiéticas e a própria evolução do sistema dependem de uma racionalidade que reconheça que a evolução jurídica se dá de forma paralela à evolução dos demais sistemas sociais.

É certo que a evolução da sociedade não pode ser prevista ou condicionada. Ao valer-se da capacidade de diferenciar-se funcionalmente, o sistema social constrói racionalidades sistêmicas que, umas para as outras, afirmam-se como entorno. Desse modo, emerge o questionamento sobre os níveis de interferência de uns sistemas sobre outros. É essa dúvida - proporcionada pela convicção quanto à realidade dos sistemas sociais autopoiéticos - que permitirá observações diferenciadas diante da tradicional busca por espécies regulativas diretas do Direito sobre a sociedade. De forma mais drástica, vale dizer que o direito contemporâneo, ao mesmo tempo em que não é determinado por outros sistemas, também não é capaz de determiná-los, rompendo com a tradicional noção sob a qual o Direito dita os rumos sociais ou é capaz de definir o que é socialmente possível e o que não o é. O sistema jurídico, dessa maneira, assimila a comunicação biotecnológica produzindo uma assimetrização temporal a partir de sua permanente reconstrução com base na distinção interior/exterior.

\section{O RISCO BIOTECNOLÓGICO COMO ATRATOR JURÍDICO}

Foi a capacidade da sociedade em ultrapassar um modelo segmentário para um modelo funcionalmente diferenciado a variável mais importante da evolução social (LUHMANN, 1987, p.218), a qual permitiu sua autodescrição a partir da ótica autopoiética e, descrevendo-se como tal, também identificou-se na forma de um sistema dotado de autonomia, diferença, repetição e historicidade. A estrutura social atual, pois, permite a análise do fenômeno jurídico como um sistema capaz de produzir 
e manter a si próprio, bem como dotado da função específica de assegurar expectativas normativas ${ }^{17}$.

É exatamente a análise do Direito como sistema autopoiético que se traduz em alternativa para uma possível gestão do risco biotecnológico, o que se dá a partir de uma constante possibilidade de variação daqueles elementos e necessidades internamente relevantes para o sistema. O risco biotecnológico, quando percebido mediante a distinção direito/não-direito, pode ser observado na forma de um atrator juridicamente condicionante, constrangendo o sistema à evolução a partir de situações que não mantém qualquer relação teleológica ou determinística, mas sim com a deriva estrutural presente na história da autopoiese sistêmica.

Objetivando minimizar a possibilidade de mal entendidos, há de se chamar a atenção para a expressão juridicamente condicionante, bem como realizar algumas aclarações teóricas necessárias à sua melhor compreensão. Antes de mais nada, vale ressaltar que o sistema jurídico pode ser visto como um sistema caótico. O caos afirma-se como o conjunto de fatores de instabilidade no qual pequenas perturbações tornam-se capazes de produzir grandes mudanças no futuro do sistema (PRIGOGINE, 2002, p.12), situação sobre a qual Prigogine define que o aumento de energia de um sistema - o que, na esfera social pode-se vislumbrar sob o incremento de complexidade por meio da incessante produção comunicativa - conduz à um igual aumento do número de trajetórias aleatórias passíveis de serem seguidas pelo sistema, tornando-o caótico (PRIGOGINE, 2002, p.58).

\footnotetext{
17 Luhmann entende o Direito como um sistema que visa a redução da complexidade - e, paradoxalmente, sua igual produção - por meio da criação de expectativas comportamentais recíprocas. Tal processo baseia-se na generalização de expectativas em três dimensões: temporal, social e prática. A generalização de expectativas em nível temporal significa sua estabilização contra eventuais frustrações por meio do processo de normatização, o que permite que a expectativa normativa adquira duração temporal mesmo no caso de desapontamento. O desapontamento pela não satisfação de uma expectativa normativa será captado e assimilado pelo próprio sistema, tornando-a imune a frustrações. Já na dimensão social há a possibilidade de institucionalização das expectativas, pois elas podem se apoiar em um eventual consenso a partir de terceiros, o que importa na presunção do consenso geral, inexistindo a necessidade de aceitação individual em relação a determinado programa legal. Por último, em sua dimensão prática, há uma projeção de expectativas sobre expectativas, o que permite que o modo de agir de alguém possa ser esperado de determinada forma por outrem mediante a programação jurídica existente no sistema. LUHMANN, 1983, p. 109.
} 
Dito de outra maneira, a incessante produção daqueles elementos que caracterizam o sistema conduz a um incrível incremento de complexidade internamente produzida, impondo ao futuro sistêmico uma grande quantidade de trajetórias possíveis. Quanto mais complexo um sistema social, maiores as suas possibilidades de decisão, logo, a não-linearidade dos sistemas caóticos conduz a um grande aumento entrópico que impõe, em tese, a incapacidade de se prever, pressupor ou determinar as trajetórias a serem seguidas pelo sistema, inclusive na seara das probabilidades (PRIGOGINE, 1996, p.81-83).

Ante a indeterminação do caos desenvolveu-se, pela física moderna, o conceito de atrator para definir um comportamento ou conjunto de comportamentos para o qual um sistema caótico é direcionado. ${ }^{18} \mathrm{~A}$ evolução do sistema encontra em um atrator um ponto para o qual o sistema é impulsionado, tomando certo caminho ao invés de outro. Tal conceito, se utilizado juntamente à noção de deriva natural (ROMESÍN; MPODOZIS, 1992, p.41) viabilizada na seara biológica por Maturana e Varela, possibilita que a indeterminação dos sistemas autopoiéticos seja mantida, contudo, acena para o reconhecimento quanto a situações comportamentais de outras esferas sociais que podem ser assumidas internamente de acordo com os critérios e interesses do próprio Direito, impulsionando a evolução.

Quando se fala do risco biotecnológico como uma comunicação que viabiliza a formação de uma multiplicidade de estados internos em diversos sistemas sociais, pode-se perceber a possibilidade do Direito em observar juridicamente outras observações sociais, bem como de construir um duplo critério evolutivo: primeiro, a construção de estruturas jurídicas viabilizadas a partir da observação quanto a comunicações de risco; segundo, a colocação da comunicação jurídica produzida como elemento capaz de causar ressonâncias em outros sistemas sociais, como a Ciência ou a Economia.

Nas duas situações o risco biotecnológico figura como um atrator sistêmico. Ao mesmo tempo em que o Direito é impulsionado à formação de novas racionalidades jurídicas - inclusive com processos internos de diferenciação - ele

18 Vide LORENZ, 1963. p. 130-141. 
igualmente produz diferença a partir da operacionalização do risco. Tal significa que o risco biotecnológico afirma-se como elemento juridicamente condicionante no sentido de que permite que o sistema evolua mediante sua consideração. $O$ atrator do sistema nesse caso não é o risco biotecnológico em si mesmo, mas aqueles comportamentos que passam a ser esperados a partir do horizonte de sentido juridicamente possível no âmbito sistêmico.

\section{A FORMAÇÃO INTERNA DA DIFERENÇA JURIDICAMENTE- CONDICIONANTE/JURIDICAMENTE-CONDICIONADO}

Pode-se afirmar que o risco biotecnológico se constitui na forma de uma comunicação que, quando observada juridicamente, conduz à formação de um conjunto de comportamentos sistêmicos específicos. Ao se afirmar como uma comunicação capaz de promover ressonâncias (LUHMANN, 1989, p.19-21) no sistema jurídico, o risco biotecnológico pode ser visto na forma de um atrator estranho, o qual não permite uma condição de determinação do estado posterior do sistema, mas, ao contrário, a observação jurídica do risco oscila de acordo com o conteúdo da irritação sofrida pelo Direito e, de igual maneira, pelo estado do sistema em um dado momento.

A instabilidade do sistema permite que o Direito seja permanentemente reconstruído a partir de suas próprias necessidades, erigindo horizontes de sentido jurídico diante de situações indeterminadas espacial e temporalmente. Essa constatação torna visível que, se o caos é a realidade do Direito, a única ordem viável é aquela construída a partir dessa incapacidade de previsão ou determinação do estado posterior do sistema. A ordem jurídica, em seu sentido de organização e estruturação, apenas é possível distante de qualquer determinismo, pois "nenhuma medida, nenhum cálculo leva estritamente a um ponto, à consideração de uma trajetória 'única'; estaremos sempre diante de 'conjuntos' de trajetórias" (PRIGOGINE, 2002, p.51). Tal conjunto de trajetórias, entretanto, pode ser influenciado diante de certas circunstâncias. É certo que "a história do sistema, como um todo, pode levar, 
por certas 'bifurcações' nas decisões, a estados de estabilidade" (TEUBNER, 2005, p.37), sendo construída a partir de limites decisórios e cognitivos que condicionam o futuro e a evolução. $O$ enfrentamento do tema a partir da consideração de atratores juridicamente condicionantes produz uma reviravolta quanto às condições sistêmicas para a evolução da capacidade regulatória do Direito.

Pois bem. No mesmo momento em que a evolução jurídica pode ser observada desde o risco biotecnológico como elemento conducente à formação de atratores juridicamente condicionantes, os quais impulsionarão o sistema do Direito a novas formas de auto-observação e autodescrição, também produz observações quando a construção de atratores juridicamente condicionados. Enquanto aquele, como visto, se afirma como um conjunto de comportamentos assumidos pelo sistema a partir da consideração do risco das biotécnicas, este reflete a forma pela qual se faz visível o rompimento para com a regulação da sociedade por meio do Direito e a consequente assunção de formas de regulação indireta.

Fático é o reconhecimento quanto à crise de efetividade que assola a prática jurídica. Essa crise de regulação é denunciada, sob as lentes sistêmicas, entre outros, por Rocha (2009, p.37) e Carvalho (2013, p.46-47), conduzindo à percepção - desde a ótica da Ciência - de que, por um lado, o Direito enclausura-se operativamente, tornando-se impossível sua determinação por outros sistemas, bem como sua intervenção direta em outras esferas sociais, impossibilitando a regulação direta da sociedade e de seus subsistemas pelo Direito. Além dessa crise regulatória externa, o sistema jurídico também enfrenta problemas internos, relacionados com a incapacidade da dogmática jurídica em assimilar novos problemas produzidos pela sociedade contemporânea, o que se dá em razão de sua operacionalização mediante uma lógica unicamente condicional que não mais é compatível com a hipercomplexidade do momento atual (CARVALHO, 2013, p.50-51).

Poder-se-ia dizer le Roi est mort, vive le Roi $^{19} \mathrm{em}$ relação ao direito regulatório ou ainda, vê-lo sob a perspectiva de uma morte anunciada como o fez Teubner

\footnotetext{
${ }^{19}$ O Rei está morto. Viva o Rei. Expressão cunhada por ocasião da coroação de Carlos VII, da França após o falecimento do monarca anterior, Carlos VI, a qual designa a transferência dos poderes do monarca falecido ao soberano recém proclamado.
} 
parafraseando a observação literária de García Márquez (TEUBNER, 2005, p.24-27; MÁRQUEZ, 2001). A morte anunciada do direito regulatório exige novas perspectivas jurídicas para o enfrentamento dos problemas produzidos pela sociedade sob a forma de uma regulação contextual, a qual pode ser pensada a partir de um intervencionismo capaz de criar condições necessárias para o desenvolvimento dos atratores desejados (TEUBNER, 2005, p.39).

É nesse contexto que a consideração da comunicação jurídica na forma de atratores juridicamente condicionados permite a regulação. Se a regulação direta entre diferentes esferas sociais não é possível, uma alternativa para tal problema é a construção de condições para uma regulação indireta ou reflexiva entre Direito e sociedade. Nesse aspecto, concordando com Teubner, é possível que a comunicação jurídica seja direcionada de modo a causar perturbações em outras esferas sociais, constituindo-se na forma de um atrator firmado desde a perspectiva jurídica. Ainda que arriscada, tal estratégia permitiria que verdades juridicamente construídas fossem assimiladas sob os pontos de observação de outras esferas sociais, possibilitando não uma regulação pelo Direito, mas uma regulação indireta que se construiria a partir do Direito.

Quando se fala em atratores juridicamente condicionantes e atratores juridicamente condicionados tem-se em perspectiva exatamente a alocação da distinção interno/externo no interior jurídico. Internamente a evolução jurídica torna-se condicionada àquelas necessidades produzidas pelo risco biotecnológico enquanto produto social, desde que tal risco seja percebido pelo sistema jurídico, o que possibilita a alteração nas estruturas do Direito pelo próprio Direito. Externamente, o sistema torna-se capaz de influenciar comportamentos de outros observadores desde construções orientadas à produção de perturbações específicas a serem observadas por outras racionalidades sociais.

Ressalte-se que a distinção interno/externo ou, de forma mais incisiva para o presente escopo, a diferença condicionante/condicionado apenas é possível desde o próprio Direito. O condicionamento jurídico não é possível desde fora do sistema ou promovido por qualquer outra autoridade que não a do próprio sistema jurídico. Tal constatação impõe o reconhecimento quanto à internalização da distinção 
interno/externo na elaboração daquelas operações que são particulares ao sistema do Direito.

Assim sendo, é a realidade do Direito que possibilita a discussão quanto aos atratores condicionantes/condicionados, viabilizando que sua prática seja direcionada desde a consideração do risco biotecnológico: internamente, como critério evolutivo; externamente, como possibilidade de regulação, ainda que esta segunda hipótese caracterize-se, e igual maneira, como um produto internamente produzido. A formação da distinção condicionante/condicionado depende, contudo, daquelas condições apenas possibilitadas pela historicidade do sistema do Direito. A visualização do risco biotecnológico como atrator evolutivo condicionante/condicionado não soluciona a problemática da contingência da distinção geneticamente-aplicável/geneticamenteinaplicável, mas, ao contrário, afirma a possibilidade de que, diante da não solução do problema, existam caminhos passíveis de construção pelo Direito.

As estruturas sociais tornam-se factíveis apenas a partir de uma canalização que vai de uma operação a outra, permitindo que a referência à comunicação deixe um campo aberto para novas possibilidades e, com isso, exponha as estruturas sociais à evolução (LUHMANN, 2007, p.339). Logo, se a evolução é possível apenas a partir de uma referência ampla a um universo de comunicações selecionáveis, o risco biotecnológico como atrator permite que esse mesmo universo mantenha-se como um horizonte decisório, porém, ao mesmo tempo acena para possibilidades de trajetórias que, caso seguidas, vincularão o futuro do sistema.

No plano da práxis jurídica pode-se observar como atratores juridicamente condicionantes aqueles comportamentos das estruturas jurídico-dogmáticas tendentes a solucionar problemas relacionados à biotecnologia ${ }^{20}$ quando colocadas em funcionamento diante de perturbações sofridas pelo Direito que, a partir de sua operacionalização, permite a criação de novas condições estruturais que conduzem a referência do sistema àquelas operações futuras possíveis no campo da gestão do risco biotecnológico. Internamente, o risco biotecnológico como atrator juridicamente condicionante permite que a recursividade das operações realizadas pelo sistema do

20 Cite-se exemplificativamente as Ações Civis Públicas, ações que objetivem a tutela específica do risco, perícias ambientais, termos de ajustamento de conduta, entre outros. 
Direito seja influenciada por aqueles critérios possíveis a partir da distinção legislação/jurisdição. Ou seja, os mecanismos que asseguram a funcionalidade do Direito a partir de sua unidade distintiva apontam para a igual possibilidade de produção de comunicações que possam vir a ser identificadas autonomamente no interior do sistema sob o símbolo de uma codificação binária ainda mais restritiva e parcial.

Por outro lado, a comunicação jurídica deve ser capaz de produzir ressonâncias em seu entorno ou, melhor dito, nos sistemas presentes em seu entorno. A segunda forma assumida pelos atratores evolutivos é possível desde a remessa das perturbações externas ao plano interno, sua operacionalização jurídica e, reflexamente, a resposta jurídica a tais perturbações. Logo, se é possível partir-se da lógica evolutiva para se observar a formação do sentido jurídico dos riscos biotecnológicos, é também possível que a mesma lógica evolutiva permita a formação de atratores juridicamente condicionados que, quando utilizados pelo Direito, apontam para a dupla finalidade da regulação indireta e da evolução sistêmica.

É na bifurcação entre duas realidades comunicativas que emerge a possibilidade de se observar a formação sistêmica de uma esfera restritiva de sentido no interior do Direito. Ao contrário da comunicação técnica, no campo jurídico a indeterminação não permite qualquer planificação racionalmente orientada ou uma utilização teleológica. Nesse sentido, partindo-se do pressuposto do Direito como sistema autopoiético, sua reprodução é possível apenas com referência à própria indeterminação, havendo, no dizer de Nicola (1997, p.238), a certeza quanto à sua existência, porém, incerteza quanto ao seu conteúdo.

A incerteza quanto ao conteúdo do direito futuro é o que assegura a liberdade evolutiva do sistema. Ao se observar o risco biotecnológico como uma comunicação capaz de se amoldar sob a distinção juridicamente-condicionante/juridicamentecondicionado, esta passa a atuar como uma comunicação que permeia o interior sistêmico e assegura a evolução por meio do tratamento jurídico que passa a ser possibilitado por meio da mencionada diferença.

Os atratores condicionantes/condicionados, portanto, relacionam-se com aqueles comportamentos esperados a partir da interação entre Direito e sociedade, 
bem como pela consideração do risco e sua assimilação jurídica. Quando o sistema reage a determinada perturbação, há a reconstrução interna daqueles pressupostos jurídicos úteis ao processamento da perturbação em questão. Em outras palavras, a percepção do risco faz com que o sistema atue sob uma tríplice estratégia cognitiva que envolve processos de variação, seleção e retenção, como definiu Teubner (1989, p.104).

Essa tríplice estratégia permite que o Direito perceba, assimile e estruture internamente o risco biotecnológico por meio de seus instrumentos dogmáticos e, ao mesmo tempo, conduz o sistema a uma realidade até então inexistente. Ao buscar estruturar internamente possibilidades de gestão de risco, o Direito se autoconstrói e, logo, ao perceber o risco biotecnológico e criar estratégias para sua gestão, igualmente coloca-se na linha de partida para novas aquisições evolutivas. Eis a circularidade.

O contexto autopoiético na qual se insere o sistema do Direito conseguiu, com base em tais estratégias, construir uma realidade jurídica na qual o risco biotecnológico pôde ser objeto de tematização comunicativa. Tais estratégias podem ser observadas, por exemplo, pela formação dos princípios da precaução e prevenção e sua aplicação como forma de gestão de risco, pela irritação política promovida pela Lei 11.105/2005, na qual criou-se o Conselho Nacional de Biossegurança (CNBS), reestruturou-se a Comissão Técnica Nacional de Biossegurança (CTNBio), previu a Política Nacional de Biossegurança, entre outras disposições, bem como pela atuação dos tribunais mediante a constatação e assimilação do risco biotecnológico desde o centro do sistema do Direito.

Ao entrarem em funcionamento, esses mecanismos passam a assumir comportamentos específicos tendentes a assegurar a gestão dos riscos advindos da distinção geneticamente-aplicável/geneticamente-inaplicável. Além disso, ao se observar tais mecanismos como elementos que, a seu modo, direcionarão o sistema para determinada trajetória, tem-se sua caracterização vinculada à formação de atratores evolutivos que possuem nos comportamentos jurídicos próprios à gestão do risco biotecnológico seu ponto de convergência. 
A partir daí, o problema que se coloca diz respeito à reiteração da comunicação jurídica quando em referência a questões relacionadas à biotecnologia. Sabe-se que a recursividade das operações sociais permite o desenvolvimento de racionalidades sistêmicas parciais capazes de cumprir funções específicas (LUHMANN, 1993, p.327). Como já referido, tais funções são cumpridas por esferas comunicativas restritivas que adquirem autonomia diante da sociedade e passam a operar com base em uma referência binária à suas estruturas e operações. A situação se agrava, porém, quando se reconhece o desenvolvimento de comunicações parciais no interior de sistemas funcionais autônomos, impondo a estes uma subdiferenciação interna.

A reiteração de comunicações que se amoldam sob a forma do risco biotecnológico fornece ao Direito uma complexidade tal que coloca o sistema em funcionamento no intuito de incrementar sua própria complexidade interna para a redução da complexidade de seu entorno. Sendo um sistema reflexivo, no momento em que o Direito se ocupa com o risco biotecnológico ele passa a produzir uma reiteração comunicativa capaz de permitir níveis de recursividade tais que direcionam a comunicação à formação intrasistêmica de distinções específicas. Com isso, ainda que a comunicação do sistema do Direito mantenha sua referência primária à distinção direito/não-direito, a recursivização daquelas comunicações jurídicas com referência à biotecnologia passam a formar uma cadeia autorreferencial capaz de diferenciar-se de outras comunicações também jurídicas capazes de contribuírem para a gestão do risco biotecnológico.

\section{CONCLUSÃO}

Visto como um sistema caótico, os estados internos do Direito não são passíveis de determinação ou previsão. Sabe-se que existe e continuará existindo um sistema jurídico, porém o resultado de suas operações varia de instante para instante, sugerindo que a sociedade ou outros sistemas no entorno jurídico não são minimamente capazes de orientar, controlar ou delimitar os estados internos do 
Direito. Não obstante, a identificação da comunicação biotecnológica de risco na forma de atrator sistêmico pressupõe que esta seja capaz de influenciar a comunicação jurídica mediante uma convergência de comportamentos assumidos pelo Direito, um internamente, outro externamente.

Ao se assumir a possibilidade de evolução do sistema jurídico, o risco biotecnológico passa a influenciar nas possíveis trajetórias adotadas pelo sistema, não condicionando-a no sentido lato da expressão, mas possibilitando ao sistema utilizar o risco biotecnológico como norteador de suas operações internas (atrator juridicamente condicionante), bem como de sua capacidade de produzir ressonâncias direcionadas em outros sistemas sociais (atrator juridicamente condicionado). O risco atravessa os mais diversos sistemas sociais, constrangendo o Direito à sua assimilação. A consideração do risco promove um exponencial aumento de complexidade na sociedade, a qual descarrega tais indeterminações no sistema jurídico para que sejam estabelecidas expectativas generalizadas congruentes. Tal comportamento social faz com que o risco seja percebido como um atrator evolutivo do sistema jurídico, demarcando possibilidades de estados internos mediante sua percepção pelo Direito, o que aponta para a formação de um sentido jurídicobiotecnológico internamente construído.

O conjunto de comportamentos jurídicos atrelados ao risco biotecnológico passa a produzir operações circulares, cuja reiteração redunda na formação de um sentido parcial à comunicação resultante da juridicização do risco biotecnológico. Além da percepção jurídica do risco biotecnológico e sua utilização na forma de um atrator sistêmico, a abertura do Direito às perturbações biotecnológicas redunda na formação de uma forte especificação de sentido no interior do Direito, encontrando-se a reiteração circular de uma comunicação parcial intrasistêmica como elemento condicionante para a construção de posteriores formas de gestão de risco.

\section{REFERÊNCIAS}

CARVALHO, Délton Winter de. Dano ambiental futuro: a responsabilização civil pelo dano ambiental. 2. ed. Porto Alegre: Livraria do Advogado, 2013. 
DARWIN, Charles. A origem das espécies. Portugal: Planeta Vivo, 2009.

HEGEL, Georg Wilhelm Friedrich. A razão na história: uma introdução geral à filosofia da história. São Paulo: Centauro, 2001.

LORENZ, Edward Norton. Deterministic nonperiodic flow. Journal of the atmospheric sciences, Boston: American Meteorological Society. v. 20, n. 2. mar. 1963.

LUHMANN, Niklas. Límites de la comunicación como condición de evolución. Revista de Occidente, Madrid: Fundación Ortega Y Gasset, n. 118, mar., 1991. p. 23-40.

Sociologia do direito. v. I. Rio de Janeiro: Tempo Brasileiro, 1983.

A estabilidade instável. In: SILVA, Juremir Machado da. O pensamento do fim de século. Porto Alegre: L\&PM, 1993. p. 218-219. Entrevista concedida a Juremir Machado da Silva, realizada em Porto Alegre, em setembro de 1990.

. A posição dos tribunais no sistema jurídico. Ajuris, Porto Alegre, Ajuris, n. 49, ano XVII, jul., 1990.

Arte, diálogo de surdos-mudos? Então, Porto Alegre, ano 1, n. 4., nov. 1990. Entrevista concedida a Luciano Afonso e Maria Tomaselli, realizada em Porto Alegre, em novembro de 1990.

El derecho de la sociedad. 2. ed. México: Herder/lberoamericana, 2005.

. La clausura operacional de los sistemas psíquicos y sociales. In: FISHER, Hans Rudi; RETZER, Arnold; SCHWEITZER, Jochen (Comp.). El final de los grandes proyectos. Madrid: Gedisa, 1997. p. 118-119 e 127.

. La costituzione come acquisizione evolutiva. In: ZAGREBELSKY, Gustavo; PORTINARO, Pier Paolo; LUTHER, Jörg. II futuro della costituzione. Torino: Einaudi, 1996.

- La sociedad de la sociedad. Ciudad de México: Universidad Iberoamericana/Herder Editorial, 2007.

La teoría de la diferenciación social. Revista de Occidente, Madrid: Fundación Ortega Y Gasset, n. 74-75, jul-ago., 1987.

Sistemas sociales: lineamentos para una teoría general. Barcelona/México/Santafé de Bogotá: Anthropos/ Universidad Iberoamericana/CEJA. 1998. 
NAFARRATE, Javier Torres. La des-diferenciación como consecuencia de la diferenciación por funciones de la sociedad en la teoría de Luhmann. Acta Sociológica, Ciudad de México: Centro de Estudios Sociológicos de la UNAM, n. 59, set-dez., 2012.

NICOLA, Daniela Ribeiro Mendes. Estrutura e função do direito na teoria da sociedade de Luhmann. In: ROCHA, Leonel Severo. Paradoxos da auto-observação: percursos da teoria jurídica contemporânea. Curitiba: JM, 1997.

PARSONS, Talcott. O sistema das sociedades modernas. São Paulo: Pioneira, 1974

PRIGOGINE, llya. As leis do caos. São Paulo: Unoesp, 2002.

O fim das certezas: tempo, caos e natureza. São Paulo: Editora da Universidade Estadual Paulista, 1996.

ROCHA, Leonel Severo. Da epistemologia jurídica normativista ao construtivismo sistêmico. In _ ; SCHWARTZ, Germano; CLAM, Jean. Introdução à teoria do sistema autopoietico do direito. Porto Alegre: Livraria do Advogado, 2005.

ROMESÍN, Humberto Maturana; MPODOZIS, Jorge. Origen de las especies por medio de la deriva natural. Santiago: Museo Nacional de Historia Natural, 1992.

; VARELA, Francisco. A árvore do conhecimento: as bases biológicas da compreensão humana. São Paulo: Palas Athena, 2001.

SPENCER, Herbert. Do progresso: sua lei e sua causa. Lisboa: Inquérito, 1939.

TEUBNER, Gunther. Direito, sistema e policontexturalidade. Piracicaba: Unimep, 2005. Gulbenkian, 1989.

. O direito como sistema autopoiético. Lisboa: Fundação Calouste 